To the Editors:

\title{
Vasopressin as an inotrope in refractory septic shock
}

Until recently vasopressin was commonly used as an antidiuretic to treat diabetes insipidus, and to control haemorrhage due to oesophageal varices. We report a woman with refractory hypotension due to severe sepsis whose blood pressure was maintained with vasopressin until the septic focus was drained.

A 64-year-old hypertensive woman was admitted to the intensive care unit with hypotension, tachycardia and dyspnoea of about 6 hours duration. She had undergone

Vol. 55, No. 1, March 2010 oesophagectomy for carcinoma of the esophagus 15 days ago. She also had high fever and neutrophil leucocytosis. Her heart rate was 142/minute and the blood pressure (BP) was $70 / 40 \mathrm{mmHg}$ despite dopamine infusion. There were coarse crackles and reduced breath sounds in the lower zone of the right lung. Central venous pressure (CVP) and arterial blood pressure were monitored and she was ventilated. Although the CVP was $18-20 \mathrm{cmH}_{2} \mathrm{O}$, her $\mathrm{BP}$ remained $75 / 40 \mathrm{mmHg}$ despite infusions of dobutamine 20 $\mu \mathrm{g} / \mathrm{kg} / \mathrm{min}$, noradrenaline $0.4 \mu \mathrm{g} / \mathrm{kg} / \mathrm{min}$, dopamine $20 \mu \mathrm{g} /$ 
$\mathrm{kg} / \mathrm{min}$ and adrenaline $0.4 \mu \mathrm{g} / \mathrm{kg} / \mathrm{min}$, and intravenous hydrocortisone.

As her hypotension was refractory to the treatment given, she was started on a vasopressin infusion at an initial dose of 0.02 units/ $\mathrm{min}$, which was later increased to 0.04 units/min. Her blood pressure increased to $120 / 75$ $\mathrm{mmHg}$ within 2-3 hours, and was maintained at this level for the next 24 hours. The mixed venous (CVP) oxygen saturation increased from $55 \%$ to $68 \%$, and the base excess and urine output also improved. A chest radiograph showed a fluid collection in the right hemithorax, and a right minithoracotomy was performed to drain the purulent fluid. During the next 48 hours inotropic and vasopressor requirements declined, and were tailed off. She had no evidence of digital or coronary ischaemia during vasopressin infusion.

Vasopressin restores vascular tone in vasoplegic (catecholamine resistant) shock by at least four mechanisms: through activation of V1 vascular receptors, modulation of ATP-sensitive potassium channels, modulation of nitric oxide (NO), and potentiating adrenergic and other vasoconstrictor agents [1]. Studies show elevation of vasopressin concentrations in early septic shock, but with continued shock, concentrations decrease to the normal range in the majority of patients [2]. This is called "relative vasopressin deficiency", because in the presence of hypotension, vasopressin levels can be expected to be high. A recent randomised, controlled trial (Vasopressin in Septic Shock Trial) comparing norepinephrine (noradrenaline) alone to norepinephrine plus vasopressin infusion at a dose of 0.03 units/min in patients with septic shock showed no difference in mortality at 28 days [3]. However, in patients with less severe grades of septic shock, the 28 day mortality was lower in the vasopressin group.

Our patient also had catecholamine resistant shock, as she did not respond to maximal doses of inotropic and vasopressor agents. Vasopressin was given at a dose of 0.04 units/min, and haemodynamic improvement was noted within 2-3 hours. Studies have not shown adverse cardiac effects related to low dose vasopressin. Our patient also did not have any evidence of coronary ischaemia during treatment with vasopressin.

\section{References}

1. Holmes CL, Landry DW, Granton JT. Vasopressin and the cardiovascular system - clinical physiology. Critical Care 2004; 8: 11-23.

2. Sharshar T, Blanchard A, Paillard M, et al. Circulating vasopressin levels in septic shock. Critical Care Medicine 2003; 31: 1752-8.

3. Russell JA, Walley KR, Singer J, Gordon AC, et al. Vasopressin versus norepinephrine infusion in patients with septic shock. New England Journal of Medicine 2008; 358: 877-87.

\section{B W P Habaragamuwa ${ }^{1}$, N Lamahewage ${ }^{1}$ and C A G S Piyasiri ${ }^{1}$}

${ }^{1}$ Department of Anaesthesiology, Colombo South Teaching Hospital, Sri Lanka.

Correspondence: BWPH, e-mail <buddhikah@hotmail.com>. Received 12 October 2008 and revised version accepted 12 August 2009. Competing interests: none declared. 